\title{
Self-esteem and mental health in adolescents - level and stability during a school year
}

\author{
Unni Karin Moksnes ${ }^{1}$ and Randi Johansen Reidunsdatter ${ }^{2}$ \\ 1) Department of Public Health and Nursing / NTNU Center for Health Promotion Research, Norwegian \\ University of Science and Technology, Trondheim, Norway \\ 2) Department of Circulation and Medical Imaging, NTNU, Norwegian University of Science and Technology, \\ Trondheim, Norway \\ Correspondence: Unni Karin Moksnes, Department of Public Health and Nursing / NTNU Centre for Health Promotion Research, Norwegian \\ University of Science and Technology, NO-7491 Trondheim, Norway \\ E-mail: unni.moksnes@ntnu.no Telephone+4797114742
}

\begin{abstract}
Aim: Adolescence represent an important period for positive mental health development. The aim of the present paper was to investigate gender differences as well as the level, stability and predictive role of mental health (symptoms of depression/anxiety and mental well-being) and self-esteem in adolescents during a school year.

Methods: The study sample consisted of a cohort of 351 students aged 15-21 years in Mid-Norway. In a survey administrated at the beginning and end of the 2016/2017 school year, mental well-being was assessed with Warwick-Edinburgh Mental Well-Being Scale, depression/anxiety with Hopkins Symptom Checklist and self-esteem with the Rosenberg Self-Esteem Scale. Two models were tested for prediction; self-esteem on mental health (vulnerability model) and mental health on self-esteem (scar model).

Results: Girls reported significantly higher depression/anxiety than boys and showed a slightly significant increase in depression/anxiety, stress and self-esteem during the two assessments. Boys scored significantly higher on mental well-being and self-esteem and reported stable mental health during the school year. Selfesteem significantly predicted depression/anxiety and mental well-being. Mental well-being and depression/ anxiety also significantly predicted self-esteem.

Conclusion: The results suggest that self-esteem and mental health are reciprocally associated. The results underline the gender differences in overall mental health in adolescents and thus the potential importance of acknowledging gender when working on universal strategies for positive mental health development.
\end{abstract}

This is an open access article distributed under the Creative Commons Attribution Licence, which permits unrestricted use, distribution, and reproduction in any medium, provided the original work is properly cited.

\section{INTRODUCTION}

Mental health is integral to a populations health and quality of life $(\mathrm{QoL})$ and contributes to the functioning of individuals, families, communities and the social and economic prosperity of society (1). WHO defines mental health as 'a state of well-being in which every individual realizes his or her own potential, can cope with the normal stresses of life, can work productively and fruitfully, and is able to contribute to his or her community (1). The breadth of this definition is of interest as it includes both subjective well-being, psychological, physiological and social functioning, and constitutes a complementary viewpoint to the biomedical perspective focussing on risks for mental symptoms and disease $(1,2)$. The understanding of well-being emphasizes both the individual's emotions and functioning, where hedonia and eudaimonia have been central theoretical approaches (2). Adolescence represents an important period for positive mental health development. Although most adolescents report good health and high levels of well-being, the transition into adolescence seems to be a decisive period for development of mental health problems (3). Knowledge of vulnerability and protective factors associated with mental health are essential for understanding adaptive and maladaptive development during adolescence. Central questions stated in this article are therefore how do adolescents' mental health develop during significant periods in life and which factors predicts positive and negative mental health outcomes during adolescence?

In Norway, it is estimated that $15-20 \%$ of children and adolescents have reduced function due to mental symptoms, most commonly depression, anxiety and behavioural problems (3). Of these, approximately $7 \%$ have such severe symptoms that meet the requirements for a psychiatric diagnosis $(3,4)$, with a strong female preponderance, especially in depressive symptoms $(3,5)$. The explanation of mental health problems is complex and includes understanding of the individual's biological, psychological and psychosocial factors and vulnerabilities $(3,5)$. Some of the factors associated with mental health problems are chronic non-specific pain $(6,7)$, exposure to acute and chronic stressors and low self-esteem $(3,5,8)$.

Self-esteem is an essential part of the individual's self-concept and regarded important for positive mental health and functioning during adolescence (8). Rosenberg (9) define self-esteem as the individual's 
set of thoughts and feelings about his or her own worth and importance, which reflects the notion of "global" self-esteem or self-worth. Self-esteem is thus the evaluative and affective dimension of the self-concept and is susceptible to multiple internal and external influences and changes during adolescence $(10,11)$.

There is some disagreement in the literature as to whether self-esteem is a stable or changing personal characteristic. Although individuals may differ in the particular trajectory they follow, self-esteem seem to increase from adolescence to middle adulthood, peak about age 50 to 60 years and then decrease into old age (11-13). Self-esteem also seem to show different trajectories during adolescence $(10,14,15)$, suggesting that self-esteem is a relatively stable but by no means an immutable trait, with considerable individual differences. With regard to gender differences, studies have found that males seem to report higher self-esteem than females $(13,16-18)$. However, these differences generally tend to be small and self-esteem seem to increase in both genders from adolescence to midlife and then declines in old age (19).

There is an ongoing debate whether individuals with high self-esteem have better prospects in life than individuals with low self-esteem (11). The importance of self-esteem is underscored by decades of theory development and research supporting low self-esteem as a predictor of symptoms of depression and anxiety $(8,11,20-23)$. Strong self-esteem is also related to higher life satisfaction $(8,24-26)$ and seem to be a protective factor through its role as a potential buffer against negative stressors $(21,27)$.

Two models have been proposed to explain the association between low self-esteem and symptoms of depression. The vulnerability model states that low self-esteem is conceptualized as a personality factor that predisposes the person to experience depression. Although its specificity may vary, vulnerability refers to the susceptibility or predisposition of an individual to negative outcomes. In the case of self-esteem, negative evaluation of the self is not just a symptom of depression but play a critical causal role in its aetiology. The link between predisposition and outcome can be mediated or moderated by other factors $(12,27)$. The scar model proposes that low self-esteem is a consequence, rather than a cause of depression, because experiences of depression may leave permanent scars in the self-concept of the individual. Both models may interact in the understanding of the link between selfesteem and depression, but moreover, strongest support is found for the vulnerability model, which holds across different samples and study designs $(12,22)$. The vulnerability model and the scar model has also been investigated in relation to symptoms of anxiety, showing support for both models (20). However, further research is needed to test the impact of selfesteem, especially in relation to mental well-being.

Moreover, studies have investigated self-esteem over longer periods from late adolescence to adulthood and old age $(10,19)$. Less attention is paid to examining change or stability of these constructs over shorter, and particularly significant transitional periods during adolescence, such as the period of secondary high school $(10,11,14)$. Based on the assumption that mental health can be promoted by improving self-esteem, it is of importance to investigate the associations between self-esteem and mental health in adolescents.

The aims of the present study were therefore to investigate:

1. The level, stability and gender differences in selfesteem and mental health in adolescents during a school year

2. The predictive role of self-esteem on mental health and the predictive role of mental health on selfesteem in this population

\section{METHOD}

\section{Participants}

The study sample consisted of a student cohort associated to four public upper secondary schools in Trondheim municipality in Mid-Norway. The schools represent Norwegian public upper secondary schools, which are relatively similar in socio-demographic terms. A study specific questionnaire was administered by teachers at two time points, in the beginning and in the end of the 2016/2017 school year (T1: September 2016, T2: April-June 2017). Five schools originally agreed to participate in the study, but one school withdrew before the T2 assessment. At T1, the questionnaire was administered to 2,145 of the 3,281 students at the five schools, and 2,087 students responded with usable information (response rate 97.3\%). At T2, the questionnaire was administered to 1,127 of the 2,811 students at the four schools, and 1,054 students responded with usable information (response rate 93.5\%). In the present study, only students that responded at both time points and those aged 15-21 years was included (as this age range is representative for students in secondary high school), providing a sample of 351 students.

\section{Procedure}

The data collection was approved by the Regional Committee for Medical Research Ethics Mid-Norway (REK 2014/1996). Prior to data collection, a written information letter and an information video was available to all students and parents on the school's elearning platform. Written information was also given to all students in the questionnaire. In addition, all first-year students received an information letter including a consent form for parents to sign if students were $\leq 15$ years. Students 16 years and older gave consent to participate by answering the questionnaire. Teachers were responsible for administering the questionnaires during a 45-minute classroom session of their choice. Prior to questionnaire administration, the teacher in- 
formed the students by reading loudly the study information letter stating the aim of study and the voluntariness of participation. Questionnaire administration was completed with help from teachers in whole class groups during one regular $45 \mathrm{~min}$ school session.

\section{Assessments}

In the present study, mental health was assessed by mental well-being and symptoms of depression and anxiety. The following instruments were utilized:

Mental well-being: The 14-item version of WarwickEdinburgh Mental Well-Being Scale (WEMWBS) was used to assess mental well-being $(28,29)$. The respondents were asked how they had felt about seven positively worded statements over the past two weeks. The response scale ranged from (1) None of the time to (5) All of the time, where higher sum scores indicated higher mental well-being (range 14-70). The WEMWBS has been validated in the general population (2), clinical samples (30), and in adolescents (31-33). Cronbach's alpha for the scale in the present study was .88 (T1) and .90 (T2).

Symptoms of anxiety and depression: The 10-item version of Hopkins Symptom Checklist was used to assess symptoms of depression and anxiety (HSCL-10) $(34,35)$. Six of the 10 items are related to depression, and four are related to anxiety (34), rated on a fourpoint scale ranging from (1) Not at all to (4) Extremely; higher mean scores indicate a higher severity of anxiety and depression symptoms. The respondents had to answer at least seven out of 10 items in order to get a valid score on the scale (35). HSCL-10 is a wellused and validated scale among adolescents $(34,35)$. Cronbach's alpha for the scale in the present study was .92 (T1) and .93 (T2).

Self-esteem: The 10-item Rosenberg Self-Esteem Scale (9) was used to assess global self-esteem. The items are rated on a four-point Likert scale, ranging from (1) strongly disagree to (4) strongly agree, where higher sum score on the scale indicates higher levels of global self-esteem (range 10-40). The instrument has shown high reliability (Cronbach's alpha coefficient .86) (36) and has been validated in the adolescent population (37). Cronbach's alpha for the scale in the present study was .92 both in T1 and T2.

Stress: The Norwegian version of the Adolescent Stress Questionnaire (ASQ-N) was used to assess adolescents' experience of stress $(36,38,39)$. The ASQ is originally a 56-item inventory designed to measure normative stressors that adolescents may experience in their daily life (38). Validations of the Norwegian version of the ASQ have reduced the scale to 30-items (39). Adolescents report the extent to which any recent stressor experience has constituted a psychological challenge for them during the last year on a five-point Likert scale, ranging from (1) not at all stressful or is irrelevant to me to (5) very stressful; higher sum score indicates higher stress level (range 30-150). The ASQ has been validated in different adolescent samples showing acceptable reliability and construct validity $(40,41)$. The ASQ-N has shown to be a valid and reliable instrument for use in adolescents $(36,39)$. Cronbach's alpha for the scale in the present study was a.95 in both samples.

Pain: Symptoms of physical health problems was assessed by an 11-items scale, previously used as an idex in several studies $(6,42,43)$. The adolescents were asked if they had experienced any pain not related to any known disease or injury during the last three months. The pain was assessed in reference to headache/migraine, neck/shoulder pain, lower back/buttocks, neck/shoulders, chest, stomach, arms, and legs. Each item is ranged from (1) never/seldom (2) once a month, (3) once a week, (4) more than once $a$ week and (5) almost every day. The scale was constructed as a sum score ranging from 11-55, where higher scores indicated higher severity of pain. Cronbach's alpha for the present scale in the present study was $\alpha .82$.

Socioeconomic status: Mothers' and fathers' education were assessed separately by one item: "What is your parents' highest education?" (1) Primary and lower secondary school (2) Upper secondary school (3) University up to 4 years (4) University, more than 4 years, (5) Don't know. The two items were used as a summed index ranging from low to high education, where the value 'don't know' was excluded. Adolescents' perception of family economy was assessed by one item: "How has the family economy been during the last two years?" (1) We have had bad economy the whole time (2) We have more or less had bad economy (3) We have neither had bad or good economy (4) We have more or less had good economy (5) We have had good economy the whole time.

Field of study: Students' field of study was grouped in 'general 'and 'vocational studies'.

Parental marital status: Parental marital status was grouped in 'parents living together' and 'parents not living together'.

\section{Statistics}

All statistical analyses were carried out using SPSS, version 17.0 (SPSS, 2003). Mean scores and change scores (T2-T1) with 95\% confidence interval (CI) were calculated on all continuous scales. Gender differences in mean scores on all included scales were examined by independent samples-t-test. Pearson product-moment correlation tested bivariate associations between the continuous scales included in the multivariate analyses (not reported). Multivariate linear regression analyses were conducted to investigate the predictive role of self-esteem on mental health, and the predictive role of mental health on self-esteem, controlled for the covariates gender, age, socio-economic status (parental education and family economy) (44), stress, and pain $(3,5-7)$. P-values $\leq .05$ were considered statistically significant. 


\section{RESULTS}

\section{Characteristics of the sample}

The socio-demographic characteristics are presented in Table 1. The gender distribution of the sample was approximately equal. The majority of the sample attended general education track. Regarding parents' education as reported by the students, $49.6 \%$ of mothers and $45 \%$ of fathers had university education up to four years or more, and the rest had primary/lower secondary school or upper secondary school. Further, the majority reported that the parents lived together. Regarding the family economy, $73.8 \%$ of the students reported that they perceived that the family had good or more or less good economy, whereas only $4.3 \%$ reported that they perceived that the family had bad economy more or less all the time or all the time during the last two years.

\section{Level and stability of mental health, self-esteem and pain}

Table 2 presents mean scores (CI) and change scores (CI) of mental health, self-esteem and covariates assessed at $\mathrm{T} 1$ and $\mathrm{T} 2$. When looking at the total sample, depression/anxiety and stress increased significantly between assessment points with .09 (CI; 0.03-0.15) and 3.08 (CI; 0.66-5.50), respectively, and mental well-being decreased with 1.01 (CI; 2.02$0.00)$. Self-esteem and pain did not change significantly between assessment points.

In gender specific analyses, girls reported significantly higher mean scores than boys on depression/ anxiety, stress and pain, whereas boys scored significantly higher on mental well-being and self-esteem than girls, both at T1 and T2 (all p <.001). Girls' scores on depression/anxiety, stress and self-esteem increased significantly between $\mathrm{T} 1$ and T2 with 0.15 (CI; 0.080.23 ), 3.15 (CI; -0.03-6.33) and 1.36 (CI; 0.59-2.12) respectively, whereas boys' scores remained stable between assessment points.

\section{The predictive role of self-esteem and mental health}

The predictive role of self-esteem and mental health is presented by four regression models in Table 3 and Table 4. Girls reported significantly higher scores than boys on depression/anxiety controlled for the other variables (Model 1), but gender did not predict mental well-being (Model 2) (Table 3) or self-esteem (Model 3 and Model 4). When looking at the covariates, stronger family economy was significantly associated with higher mental well-being (Model 2). Pain and stress were both significantly associated with depression and anxiety (Model 1). Higher self-esteem predicted significantly lower levels of depression/anxiety (Model 1) and higher levels of mental well-being (Model 2), where the strongest association was found with mental well-being. Totally, the variables explained $43 \%$ of the variability in depression/anxiety (Model 1) and 39\% in mental well-being (Model 2).
Table 1. Descriptive statistics of socio-demographic variables.

\begin{tabular}{|c|c|c|}
\hline Variables & Total n (\%) & \\
\hline \multicolumn{3}{|l|}{ Gender } \\
\hline Girls & $184(52.4)$ & \\
\hline Boys & $167(47.6)$ & \\
\hline \multicolumn{3}{|l|}{ Age (years) } \\
\hline 15 & $2(0.6)$ & \\
\hline 16 & $149(42.4)$ & \\
\hline 17 & $105(29.9)$ & \\
\hline 18 & $71(20.2)$ & \\
\hline 19 & $22(6.3)$ & \\
\hline $20-21$ & $2(0.6)$ & \\
\hline \multicolumn{3}{|l|}{ Family economy } \\
\hline Bad/more or less bad economy & $15(4.3)$ & \\
\hline Neither bad or good economy & $71(20.2)$ & \\
\hline Good/more or less good economy & $259(73.8)$ & \\
\hline Missing & $6(1.7)$ & \\
\hline Parental education & Mother & Father \\
\hline Primary and lower secondary school & $15(4.3)$ & $16(4.6)$ \\
\hline Upper secondary school & $57(16.2)$ & $63(17.9)$ \\
\hline University up to 4 years & $73(20.8)$ & $54(15.4)$ \\
\hline University more than 4 years & $101(28.8)$ & $104(29.6)$ \\
\hline Don't know & $94(26.8)$ & $103(29.3)$ \\
\hline Missing & $11(3.1)$ & $11(3.2)$ \\
\hline \multicolumn{3}{|l|}{ Parents marital status } \\
\hline Parents live together & $234(64.4)$ & \\
\hline Parent do not live together & $124(34.2)$ & \\
\hline Missing & $5(1.4)$ & \\
\hline \multicolumn{3}{|l|}{ Student education } \\
\hline General & $225(64.1)$ & \\
\hline Vocational & $123(35.0)$ & \\
\hline Missing & $3(0.9)$ & \\
\hline Total & $351(100)$ & \\
\hline
\end{tabular}

Model 3 and Model 4 both indicated that depression/anxiety and mental well-being assessed at T1 predicted higher self-esteem T2, controlled for gender, age, socioeconomic status, stress and subjective pain. Overall, the models explained $13 \%$ and $27 \%$ of the variances in self-esteem.

\section{DISCUSSION}

The present study investigated level and stability in mental health (symptoms of depression/anxiety and mental well-being) and self-esteem and the predictive role of self-esteem and mental health in adolescents during a school year. Understanding the role of selfesteem in adolescents, and the reciprocal predictive role of self-esteem and mental health, is essential to facilitate a healthy mental health development in adolescents.

Gender differences was observed at the beginning of the school year for several factors; girls scored significantly higher than boys on symptoms of depression/anxiety, stress and pain, whereas boys scored significantly higher on mental well-being and selfesteem than girls.

In reference to the stability of adolescent's mental health, mental well-being decreased slightly during the school year in the total sample, but in gender specific 
Table 2. Gender differences, level and stability of self-esteem, stress, mental health and pain.

\begin{tabular}{lcccc}
\hline & \multicolumn{3}{c}{ Mean score (C.I.) } \\
\cline { 2 - 5 } & $\mathrm{n}$ & $\mathrm{T} 1$ & $\mathrm{~T} 2$ & Mean difference (C.I.) \\
\hline Mental well-being & & & & \\
$\quad$ Total & 325 & $50.37(49.17-51.39)$ & $49.36(48.41-50.80)$ & $-1.01(-2.02-0.00)$ \\
$\quad$ Girls & 173 & $48.02(46.41-49.24)$ & $46.86(45.63-48.52)$ & $-1.16(-2.40-0.08)$ \\
$\quad$ Boys & 152 & $53.05(51.27-54.36)$ & $52.22(39.89-53.65)$ & $-0.84(-2.48-0.81)$ \\
\hline Depression and anxiety & & & & \\
$\quad$ Total & 328 & $1.72(1.64-1.79)$ & $1.81(1.73-1.89)$ & $0.09(0.03-0.15)$ \\
$\quad$ Girls & 175 & $1.94(1.83-2.05)$ & $2.09(1.96-2.19)$ & $0.15(0.08-0.23)$ \\
$\quad$ Boys & 153 & $1.46(1.38-1.55)$ & $1.48(1.41-1.59)$ & $0.02(-0.07-0.10)$ \\
\hline Self-esteem & & & & \\
$\quad$ Total & 311 & $28.98(28.25-29.72)$ & $29.45(28.78-30.11)$ & $0.47(-0.13-1.06)$ \\
$\quad$ Girls & 169 & $27.04(26.00-27.88)$ & $28.40(27.64-29.36)$ & $1.36(0.59-2.12)$ \\
$\quad$ Boys & 142 & $31.29(30.00-32.00)$ & $30.70(29.69-31.60)$ & $-0.59(-1.49-0.31)$ \\
\hline Stress & & & \\
$\quad$ Total & 324 & $70.56(67.89-73.82)$ & $73.64(71.96-76.84)$ & $3.08(0.66-5.50)$ \\
$\quad$ Girls & 174 & $77.54(74.16-81.21)$ & $80.69(77.60-83.78)$ & $3.15(-0.03-6.33)$ \\
$\quad$ Boys & 150 & $62.45(58.30-66.05)$ & $65.45(62.46-68.44)$ & $3.00(-0.76-6.76)$ \\
\hline Pain & & & & \\
$\quad$ Total & 325 & $18.04(17.33-18.75)$ & $18.26(17.48-19.04)$ & $0.22(-0.43-0.87)$ \\
$\quad$ Girls & 174 & $19.71(18.70-20.61)$ & $20.28(19.18-21.28)$ & $0.56(-.18-1.30)$ \\
$\quad$ Boys & 151 & $16.11(15.22-17.03)$ & $15.93(14.91-16.95)$ & $-.18(-1.29-0.94)$ \\
\hline & & &
\end{tabular}

Table 3. The predictive role of self-esteem on depression/anxiety (Model 1) and self-esteem on mental well-being (Model 2).

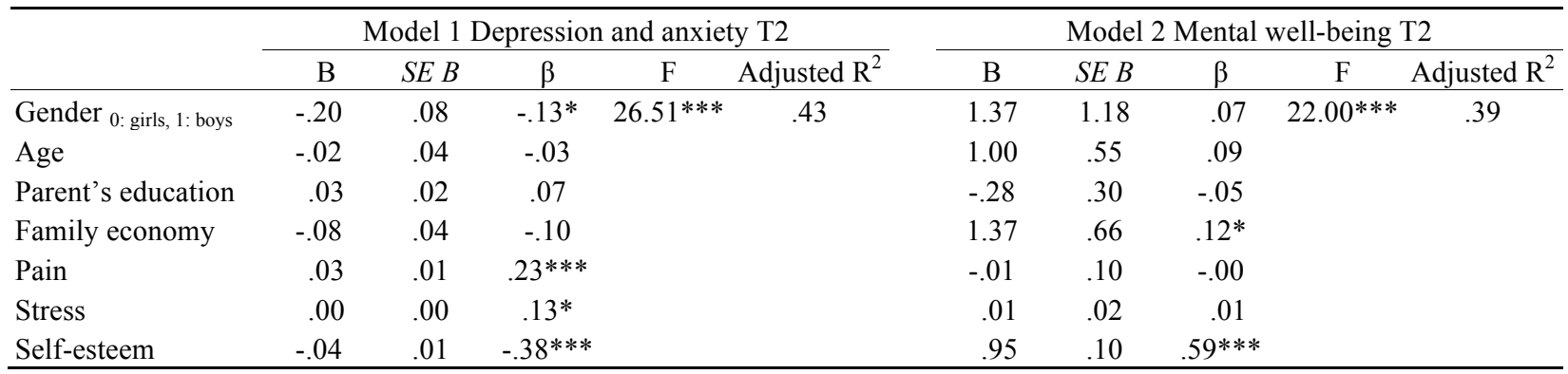

Note. Independent variables are based on T1; cases excluded listwise

$* \mathrm{p} \leq .05 ; * * \mathrm{p} \leq .01 ; * * * \mathrm{p} \leq .001$.

Table 4. The predictive role of depression/anxiety on self-esteem (Model 3) and mental well-being on self-esteem (Model 4).

\begin{tabular}{|c|c|c|c|c|c|c|c|c|c|c|}
\hline & \multicolumn{5}{|c|}{ Model 3 Self-esteem T2 } & \multicolumn{5}{|c|}{ Model 4 Self-esteem T2 } \\
\hline & $\mathrm{B}$ & $S E B$ & $\beta$ & $\mathrm{F}$ & Adjusted $\mathrm{R}^{2}$ & $\mathrm{~B}$ & $S E B$ & $\beta$ & $\mathrm{F}$ & Adjusted $\mathrm{R}^{2}$ \\
\hline Gender $_{0 \text { : girls, } 1 \text { : boys }}$ & .93 & .73 & .08 & $6.13 * * *$ & .13 & .48 & .68 & .04 & $13.63 * * *$ & .27 \\
\hline Age & .01 & .34 & .00 & & & -.08 & .31 & -.01 & & \\
\hline Parent's education & -.00 & .19 & -.00 & & & .05 & .17 & .02 & & \\
\hline Family economy & -.11 & .40 & -.02 & & & -.53 & .38 & -.09 & & \\
\hline Pain & .09 & .07 & .10 & & & -.00 & .06 & -.00 & & \\
\hline Stress & .01 & .02 & .03 & & & .01 & .01 & .04 & & \\
\hline Depression and anxiety & -3.55 & .66 & $-.44 * * *$ & & & & & & & \\
\hline Mental well-being & & & & & & .32 & .04 & $.56^{* * *}$ & & \\
\hline
\end{tabular}

Note. Independent variables are based on T1, cases excluded listwise

$* \mathrm{p} \leq .05 ; * * \mathrm{p} \leq .01 ; * * * \mathrm{p} \leq .001$. 
analyses, this small change was no longer significant. Depression/anxiety and stress increased significantly throughout the school year, and gender specific analyses revealed that the increase in depression/anxiety and stress was valid only for girls. Further, girls' selfesteem increased significantly, whereas boys' scores remained more stable during the school year.

Self-esteem refers to an individual's subjective evaluation of his or her worth as a person (9). Adolescents' development of self-esteem is susceptible to different challenges and changes in daily life and the perception by significant others is essential $(8,15,27)$. Previous studies have shown that global self-esteem is relatively high and stable over longer time spans from adolescence (14) into adulthood (10). The present study adds to these findings that the level of self-esteem seems to be high and stable over a shorter, but important time period, with a small significant increase in girls' scores. Although boys typically report higher levels of self-esteem than girls (10, 16-18), gender does not have a strong influence on the developmental trajectory of self-esteem (19). As for mental health problems, the reason for gender differences found are most likely multifactorial and may potentially result from gender role differences where girls may be more likely to internalize problems than boys. Another explanation may be differences in selfreport style where boys may have a higher threshold for reporting experiences as problematic (50).

The adolescent period naturally brings with its exposure to different potential stressors $(18,38)$. The present results showing an increase in stress levels throughout the school year may be explained by different factors such as higher exposure of school demands (e.g. exams) towards the end of the school year. The increase in stress level may thus be regarded as a normal variation in adolescents' life course. Our findings of gender differences on stress levels correspond with previous studies showing that girls are more likely to internalize the causes of stress and to report a higher stress level, especially in relation to interpersonal stressors $(18,38,39,45)$. These gender differences in stress level may also be related to the increased incidence of mental health problems especially in girls (depression, anxiety, behavioural disorders, and eating disorders) (3,5,46-48). Explanations for the development of mental health problems are complex and may include the combination of affective (emotional reactivity), biological (e.g. genetic vulnerability, pubertal timing) and cognitive factors (e.g. coping style), in interaction with environmental factors (e.g. major stress exposure, family conflict) $(46,47,49)$. The presence of one type of vulnerability may increase the likelihood of developing another type of vulnerability, thus increasing an individual's overall vulnerability to mental health problems $(3,46-48)$. The fact that girls report more symptoms of depression /anxiety than boys could partly be explained by gender roles and different reporting style.
Our findings revealed that self-esteem significantly predicted depression/anxiety, controlled for gender, age, socioeconomic status, stress and pain. Further, depression/anxiety significantly predicted self-esteem, and the associations were equally strong in both directions. These findings provide support for that low selfesteem is a general vulnerability factor for depression/ anxiety (vulnerability model) and that adolescents' report of self-esteem also might be influenced by emotional symptoms (scar model). The results support that both models are relevant in the understanding of the association between self-esteem and mental health $(12,20,27)$. However, the evidence is strongest for the vulnerability model; it holds across gender, all age groups from adolescence to old age, for affectivecognitive and somatic symptoms of depression, and for different measures of self-esteem and depression $(19,21)$. The vulnerability effect of low self-esteem on depression is suggested to operate through different pathways. An intrapersonal explanation might be that individuals with low self-esteem have more negative evaluations of the self and own coping resources (21), which may further increase the probability of poor adjustment when exposed to stressful or negative experiences, and increased vulnerability for depressive symptoms. On the other hand, a possible intrapersonal pathway for the scar effect of depression is that the experience of depression might influence self-esteem by persistently altering the way in which the individual evaluates and process self-relevant information (20).

Self-esteem is interesting both as a factor related to depressive symptoms and as an important resource for mental well-being during adolescence $(8,14,26)$. The present findings showed that self-esteem positively predicted mental well-being and that mental well-being positively predicted self-esteem, controlled for gender, age, socioeconomic status, stress experience and pain. According to Rosenberg (9), high self-esteem expresses the feeling that one is 'good enough' and individuals with high self-esteem may thus be more likely to value their self-worth positively. Individuals with high selfesteem may also be more likely to identify and use different personal and contextual coping resources, (e.g. seek and receive more social support), which may facilitate positive coping behaviours and adjustment, and promote well-being (8).

Knowledge of risk- and protective factors associated with mental health are central to the understanding of adaptive and maladaptive development during adolescence. However, there are challenges in the conceptualization of these two sets of factors and processes. One of the challenges is the difficulty of determining whether risk- and protective factors are distinct constructs or whether they exist on a continuum. In some instances, high levels of a factor such as self-esteem may protect individuals from risk, whereas low levels of the same factor amplify risk (50). The present findings supports the understanding of self-esteem as a dimension that both could be a vul- 
nerability factor and a protective factor in association with mental health.

Implementing health promoting strategies for adolescents is multifaceted and most successful when integrated into different developmental contexts in adolescents' lives (51). The school context may especially be important to facilitate intrapersonal and interpersonal resources in adolescents given the school's role as an important learning- and developmental arena for students, where school professionals and school health services have the potential to collaborate closely (52). Given the fundamental role of self-esteem for mental health in adolescents, it is important to promote adolescents' overall sense of self-worth, rather than to improve the perception of his or her intelligence, attractiveness or achievements (20). Based on the gender differences found in both self-esteem and symptoms of depression/anxiety, it may be relevant to acknowledge gender as an aspect when working with universal strategies on mental health promotion in the adolescent population.

\section{Strengths and limitations}

The study is based on a strong theoretical foundation using validated instruments for the adolescent population. Although a longitudinal study design with a short time interval was applied, effects between factors may be caused by mediating variables, which is a challenge in all observational designs. Nevertheless, longitudinal analyses are important because they can indicate whether data are consistent with a model describing the relation between the variables. All findings were based on self-reports and are therefore subject to potential self-reporting bias. Self-report requires questions where adolescents are able to reflect and understand concepts of health and illness, and to reliably evaluate and report on feelings and complaints. Meanwhile, all such data might be prone to bias due to the possible influence of social desirability factors (17). The sample of adolescents that participated at both time points was small seen in reference to the total school sample size, because different adolescents participated at $\mathrm{T} 1$ and $\mathrm{T} 2$. The results must therefore be interpreted with caution with respect to generalizability.

\section{CONCLUSION}

The present study showed stable levels of self-esteem in the total sample of adolescents during a school year, where a small increase was found for girls. Mental well-being decreased whereas depression/anxiety and stress increased slightly in the total sample, and the increase in depression/anxiety and stress was most prominent in girls. Girls reported higher levels of symptoms of depression/anxiety, stress and pain than boys, whereas boys reported higher mental well-being and self-esteem than girls. Self-esteem and mental health were found to be reciprocally associated. The results underline the gender differences in mental health in adolescents and thus the potential importance of acknowledging gender in strategies for supporting positive mental health development in adolescents.

\section{ACKNOWLEDGEMENTS}

We would like to thank all the students for their participation in the survey. We also thank the research group at NTNU Center for Health Promotion Research that have worked on this project and Trondheim Municipality for valuable collaboration.

\section{FUNDING}

This study was funded by The Research Council of Norway, grant number 238331 'Health Promotion - worthwhile? Reorienting the Community Health Care Services', and by NTNU, Norwegian University of Science and Technology.

\section{REFERENCES}

1. WHO. Promoting Mental Health. Concepts emerging evidence and practice. Summary report. World Health Organization, 2004.

2. Haver A, Akerjordet K, Caputi P, Furunes T, Magee C. Measuring mental well-being: A validation of the Short Warwick-Edinburgh Mental Well-being Scale in Norwegian and Swedish. Scand J Public Health 2015; 43: 721-727.

3. Reneflot A, Aarø LE, Aase H, Reichborn-Kjennerud T, Tambs K, Øverland S. Mental Health in Norway. The Public Health Institute. Report 2018. https://www.fhi.no/publ/2018/psykisk-helse-i-norge/.

4. Wichstrøm L, Berg-Nielsen TS, Angold A, Egger HL, Solheim E, Sveen TH. Prevalence of psychiatric disorders in preschoolers. J Child Psychol Psychiatry 2012; 53: 695-705.

5. Thapar A, Collishaw S, Pine D, Thapar AK. Depression in adolescence. Lancet 2012; 379: 1056-1067.

6. Hoftun GB, Romundstad PR, Rygg M. Factors associated with adolescent chronic non-specific pain, chronic multisite pain, and chronic pain with high disability: The Young-HUNT study 2008. J Pain 2012; 3: 874-883.

7. Skrove M, Romundstad P, Indredavik MS. Chronic multisite pain in adolescent girls and boys with emotional and behavioral problems: The Yount-HUNT study. Eur Child Adolesc Psychiatry 2015; 24: 503-515.

8. Boden JM, Fergusson DM, Horwood LJ. Does adolescent self-esteem predict later life outcomes? A test of the causal role of self-esteem. Dev Psychopathol 2008; 20: 319-339.

9. Rosenberg M. Society and the adolescent self-image. Princeton, NJ: Princeton University Press, 1965. 
10. Erol RY, Orth U. Self-esteem development from age 14 to 30 years: A longitudinal study. J Pers Soc Psychol, 2011; 102: 607-619.

11. Orth U, Robins RW, Widaman KF. Life-span development of self-esteem and its effects on important life outcomes. J Pers Soc Psychol 2012; 102: 1271-1288.

12. Orth U, Richard W, Robins W. Understanding the link between low self-esteem and depression. Curr Dir Psychol Sci 2013; 22: 455-460.

13. Orth U, Trzesniewski KH, Robins RW. Self-esteem development from young adulthood to old age: a cohortsequental longitudinal study. J Pers Soc Psychol 2010; 98: 645-658.

14. Birkeland MS, Melkevik O, Holsen I, Wold B. Trajectories of global self-esteem development during adolescence. J Adolesc 2012; 35: 43-54.

15. Baldwin SA, Hoffmann JP. The dynamics of self-esteem: A growth curve analysis. J Youth Adolesc 2002; 31: 101-103.

16. Birndorf S, Ryan S, Auinger P, Aten M. High self-esteem among adolescents: Longitudinal trends, sex differences, and protective factors. J Adolesc Health 2005; 37: 194-201.

17. Derdikman-Eiron R, Indredavik MS, Bratberg GH, Taraldsen G, Bakken IJ, Colton M. Gender differences in subjective well-being, self-esteem and psychosocial functioning in adolescents symptoms of anxiety and depression: Findings from the Nord-Trøndelag health study. Scand J Psychol 2011; 52: 261-267.

18. Moksnes UK, Moljord IEO, Espnes GA, Byrne DG. The association between stress and emotional states in adolescents: The role of gender and self-esteem. Pers Individ Dif 2010; 49: 430-435.

19. Orth U, Robins RW, Robins W. The development of self-esteem. Curr Dir Psychol Sci 2014; 23: 381-387.

20. Sowislo JF, Orth U. Does low self-esteem predict depression and anxiety? A meta-analysis of longitudinal studies. Psychol Bull 2013; 139: 213-240.

21. Orth U, Robins RW, Meier LL. Disentangling the effects of low self-esteem and stressful events on depression: Findings from three longitudinal studies. J Pers Soc Psychol 2009; 97: 307-321.

22. Orth U, Robins RW, Trzesniewski KH, Maes J, Schmitt M. Low self-esteem is a risk factor for depressive symptoms from young adulthood to old age. J Abnorm Psychol 2009; 118: 472-478.

23. Orth U, Robins RW, Roberts BW. Low self-esteem prospectively predicts depression in adolescence and young adulthood. J Pers Soc Psychol 2008; 95: 695-708.

24. Civitci N, Civitci A. Self-esteem as mediator and moderator of the relationship between loneliness and life satisfaction in adolescents. Pers Individ Dif 2009; 47: 954-958.

25. Moksnes UK, Espnes GA. Self-esteem and life satisfaction in adolescents - gender and age as potential moderators. Qual Life Res 2013; 22: 2921-2928.

26. Proctor CL, Linley PA, Maltby J. Youth life satisfaction measures: A review. J Posit Psychol 2009; 4: $128-144$.

27. Zeigler-Hill V. The connections between self-esteem and psychopathology. J Contemp Psychother 2011; 41: 157-164.

28. Stewart-Brown S, Tennant A, Tennant R, Platt S, Parkonson J, Weich S. Internal construct validity of the Warwick-Edinburgh Mental Well-being Scale (WEMWBS): a Rasch analysis using data from the Scottish Health Education Population Survey. Health Qual Life Outcomes 2009; 7: 15. doi:10.1186/1477-7525-7-15.

29. Tennant R, Hiller L, Fishwick R, et al. The Warwick-Edinburgh Mental Well-Being Scale (WEMWBS): development and UK validation. Health Qual Life Outcomes 2007; 5: 63. doi:10.1186/1477-7525-5-63.

30. Smith ORF, Alves DE, Knapstad M, Haug E, Aarø LE. Measuring mental well-being in Norway: validation of the Warwick-Edinburgh Mental Well-being Scale (WEMWBS). BMC Psychiatry 2017; 17 (1): 182.

31. Clarke A, Friede T, Putz R, Ashdown J, Martin S, Blake A, et al. Warwick-Edinburgh Mental Well-being Scale (WEMWBS): Validated for teenage school students in England and Scotland. A mixed methods assessment. BMC Public Health 2011; 11: 487.

32. McKay MT, Andretta JR. Evidence for the Psychometric Validity, Internal Consistency and Measurement Invariance of Warwick Edinburgh Mental Well-being Scale Scores in Scottish and Irish Adolescents. Psychiatry Res 2017; 255: 382-386.

33. Ringdal R, Eilertsen MEB, Bjørnsen HN, Espnes GA, Moksnes UK. Validation of two versions of the Warwick-Edinburgh Mental Well-Being Scale among Norwegian adolescents. Scand J Public Health 2018; 46: 718-725.

34. Kleppang AL, Hagquist C. The psychometric properties of the Hopkins Symptom Checklist-10: a Rasch analysis based on adolescent data from Norway. Fam Pract 2016; 33: 740-745.

35. Strand BH, Dalgard OS, Tambs K, Rognerud M. Measuring the mental health status of the Norwegian population: A comparison of the instruments SCL-25, SCL-10, SCL-5 and MHI-5 (SF-36). Nord J Psychiatry 2003; 57: 113-118.

36. Moksnes UK, Byrne DG, Mazanov J, Espnes GA. Adolescent stress: Evaluation of the factor structure of the Adolescent Stress Questionnaire. Scand J Psychol 2010; 51: 203-209. 
37. Corvyn RF. The factor structure of global self-esteem among adolescents and adults. J Res Pers 2000; 34: 357-379.

38. Byrne DG, Davenport SC, Mazanov J. Profiles of adolescent stress: The development of the adolescent stress questionnaire (ASQ). J Adolesc 2007; 30: 393-416.

39. Moksnes UK, Espnes GA. Evaluation of the Norwegian version of the Adolescent Stress Questionnaire. Scand J Psychol 2011; 52: 601-608.

40. De Vriendt T, Clays E, Moreno LA, Bergman P, Vicente-Rodriguez G, et al. Reliability and validity of the Adolescent Stress Questionnaire in a sample of European adolescents - the HELENA study. BMC Public Health 2011; 11: 717.

41. Anniko MK, Boersma K, van Wijk NPL, Byrne D, Tillfors M. Development of a shortened version of the Adolescent Stress Questionnaire (ASQ-S): construct validity and sex invariance in a large sample of Swedish adolescents. Scand J Child Adolesc Psychiatr Psychol 2018; 6: 4-15.

42. Hoftun GB, Romundstad PR, Rygg M. Association of parental chronic pain with chronic pain in the adolescent and young adult. Family linkage data from the HUNT study. JAMA Pediatr 2013; 167: 61-69.

43. Mikkelsson M, El-Metwally A, Kautianen H, Auvinen A, Macfarlane GJ, et al. Onset, prognosis and risk factors for widespread pain in school childen: A prospective 4-year follow-up study. Pain 2008; 138: 681-687.

44. Reiss F. Socioeconomic inequalities and mental health problems in children and adolescents: a systematic review. Soc Sci Med 2013; 90: 24-31.

45. Charbonneau AM, Mezulis AH, Hyde JS. Stress and emotional reactivity as explanations for gender differences in adolescents' depressive symptoms. $J$ Youth Adolesc 2009; 38: 1050-1058.

46. Graber JA, Sontag LM. Internalizing problems during adolescence. In: Lerner RM, Steinberg L (Eds.), Handbook of adolescent psychology, $3^{\text {rd }}$ edn. New Jersey: John Wiley, 2009: 642-682.

47. Essau CA, Lewinsohn PM, Seeley JR, Sasagawa S. Gender differences in the developmental course of depression. J Affect Disord 2010; 127: 185-190.

48. Hale WW, Raaijmakers Q, Muris P, Hoof A, Meeus W. Developmental trajectories of adolescent anxiety disorder symptoms: A 5-year prospective community study. J Am Acad Child Adolesc Psychiatry 2008; 47: 556-564.

49. Altemus M, Sarvaiya N, Epperson N. Sex differences in anxiety and depression clinical perspectives. Front Neuroendocrinol 2014; 35: 320-330.

50. Compas BE, Reeslund KL. Processes of risk and resilience during adolescence. In: Lerner RM, Steinberg L (Eds.), Handbook of adolescent psychology, $3^{\text {rd }}$ edn. New Jersey: John Wiley, 2009: 561-588.

51. Sawyer SM, Afifi RA, Bearinger LH, Blakemore SJ, Dick B, et al. Adolescence. A foundation for future health. Lancet 2012; 379: 1630-1640.

52. Weare K, Nind M. Mental health promotion and problem prevention in schools: what does the evidence say? Health Promot Int 2011; 26: 29-41. 